\title{
Maternal Death Caused by Severe-Critical COVID-19 in Jakarta: Case Series
}

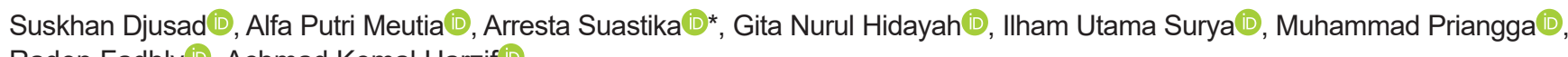
Raden Fadhly 10 , Achmad Kemal Harzif 10

Department of Obstetric and Gynecology, Faculty of Medicine, University of Indonesia, Cipto Mangunkusumo National Central General Hospital, Jakarta 10430, Indonesia

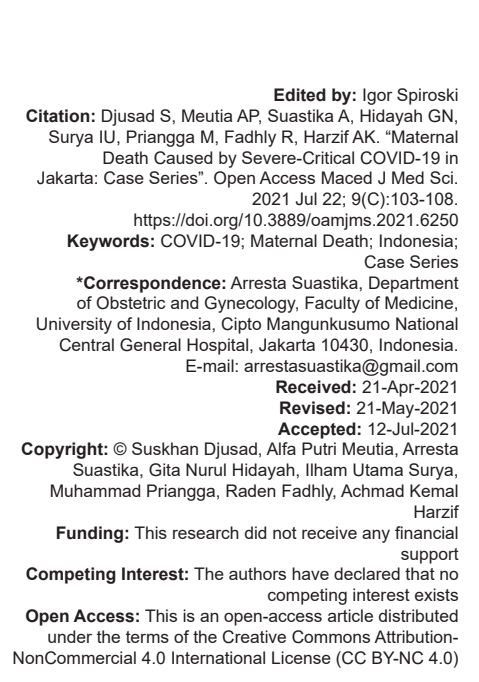

\section{Abstract}

BACKGROUND: As of January 2021, Indonesia had the 21st highest number of total COVID-19 cases and the 17th highest total deaths among all countries. COVID-19 infection in pregnant women seems to negatively affect both maternal and neonatal outcomes.

CASE REPORT: We describe four cases of pregnant women confirmed with severe and critical COVID-19 that resulted in maternal death from November until December 2020. The first case was complicated with thrombocytopenia, her condition quickly deteriorated post-delivery. Pulmonary embolism was suspected as the cause of death. Second and third cases were complicated with preeclampsia, obesity, and advanced maternal age. Second case came in sepsis condition. Her SARS CoV-2 RTPCR swab test came out after her death. Third patient did not have COVID-19 symptoms at admission. She starts having symptoms on second day and was confirmed positive a day after. She falls in septic shock. Fourth patient has history of fever, cough, and dyspnea. She was confirmed positive on firs day and her condition worsened, diagnosed with bacterial co-infection sepsis on day eight. All patients underwent cesarean section.

CONCLUSION: Limited information and studies for COVID-19 management in pregnant women are challenging for obstetricians. Management should be individualized weighing the benefit and risks in presence of comorbidities or accompanying disease.

\section{Introduction}

The pandemic caused by the novel coronavirus (COVID-19) was declared a global pandemic by the World Health Organization (WHO) on $11^{\text {th }}$ March 2020 [1]. Indonesia had the $21^{\text {st }}$ highest number of total cases and the $17^{\text {th }}$ highest total deaths among all countries in January 2021 [2]. Even though it has been more than a year since the first case announced, information known about COVID-19 is still limited, particularly its effect on pregnancy. The study reported that COVID-19 infection in pregnant women seems to negatively affect both maternal and neonatal outcomes [3]. The WHO classifies the severity of COVID-19 into three classes: non-severe, severe, and critical [4]. Comorbidities, such as cardiovascular disorders, diabetes, and obesity were risk factors for maternal death with ARDS caused by COVID-19 [5]. Risk of venous thromboembolism (VTE) is also increased in COVID-19 infection, meanwhile, pregnancy itself is widely recognized as a hypercoagulable state [6], thus pregnancy may result in further increases in the risk of maternal VTE in COVID-19 infection.

Based on CDC recommendation, the treatment of COVID-19 mainly involves infection prevention, control measures, supportive care, including oxygen therapy and mechanical ventilatory support, and antiviral therapy [7]. The RECOVERY trial, in which pregnant women were included since May 2020, reported that low dose steroid has the benefit to lower mortality among patients who received either invasive mechanical ventilation or oxygen support [8]. In pregnant women with comorbidities, management should be individualized because COVID-19 medications could worsen the comorbidities or accompanying disease. We present four cases of pregnant women confirmed with severe and critical COVID-19 resulted in maternal death during November 2020 until January 2021 in Cipto Mangunkusumo National Central General Hospital, Jakarta, Indonesia. 


\section{Case History}

\section{Case 1}

A 33-year-old woman at 38 weeks gestation was admitted to emergency room due to fever for 4 days prior to admission. She used to have a cough and shortness of breath. Before the patient was referred to our hospital, she was planned for cesarean section, but she had positive real-time PCR (RTPCR) swab test for SARS CoV-2. Obstetric examination found that the patient was in labor with transverse lie. Laboratory results showed thrombocytopenia $\left(69 \times 10^{3} / \mu \mathrm{L}\right)$ and negative Dengue NS1 antigen test. There were no comorbidities found from her history and clinical examination. She was planned for an emergency cesarean section. Post-operative she revealed stable vital signs and then admitted to high care unit and initiated on loading dose Favipiravir $2 \times$ $1600 \mathrm{mg}$. Five hours later, she was agitated and having severe dyspnea. Blood pressure abruptly drops to $74 / 41 \mathrm{mmHg}$, heart rate $110 \times / \mathrm{m}$, respiratory rate $25 \times / \mathrm{m}$, and oxygen saturation $99 \%$ with nasal cannula $3 \mathrm{lpm}$. There was no vaginal bleeding and uterine contraction was still good. Fluid therapy was initiated while waiting for post-operative laboratory results. In just $30 \mathrm{~min}$, she became hemodynamically unstable. Cardiopulmonary resuscitation was initiated, but after two times ROSC she was declared dead. Post-operative laboratory results showed: anemia ( $\mathrm{Hb} 8.8 \mathrm{~g} / \mathrm{dL})$, and thrombocytopenia $\left(78 \times 10^{3} / \mu \mathrm{L}\right)$. Pulmonary embolism was suspected as the cause of death.

\section{Case 2}

Forty-one years old woman at term pregnancy was admitted with a history of shortness of breath and premature rupture of membrane 1 day before admission. She never did antenatal care and ultrasound examination in this pregnancy. The previous day she went to midwife and was suspected for COVID-19 infection, then she was suggested to go to hospital. On the day of admission, her vital signs showed: blood pressure $167 / 100 \mathrm{mmHg}$, heart rate $154 \times / \mathrm{m}$, respiratory rate $32 \times / \mathrm{m}$, and saturation at $93 \%$ with $15 \mathrm{lpm}$ nonrebreathing mask. Her BMI was $31.6 \mathrm{~kg} / \mathrm{m}^{2}$ (obesity grade I). Crackles were heard from the pulmonary examination. Fetal heart rate could not be detected. Laboratory examination revealed leukocytosis (30.35 $\left.\times 10^{3} / \mu \mathrm{L}\right)$ and high CRP level (32.4 mg/L). She was initiated for preeclampsia management, antibiotic therapy, and planned for cesarean section. Due to the overwhelming number of COVID-19 patients at that time, Intensive and High Care Unit was full, and one ventilator was available at emergency room. In preparation for cesarean section, patient's condition has deteriorated, the medical team decided to perform perimortem cesarean section simultaneously with cardiopulmonary resuscitation. Resuscitation was continued but has no response and the patient was declared dead $15 \mathrm{~min}$ after cesarean section. The RTPCR swab test for SARS CoV-2 thereafter was positive.

\section{Case 3}

A41-year-old woman at 40 weeks of pregnancy was referred with preeclampsia and positive COVID-19 antibody test. Her blood pressure was 166/91 mmHg. Further examination shown second stage of labor with fetal distress, thus, she was planned for emergency caesarean section. Laboratory results showed anemia (hemoglobin level $10.1 \mathrm{~g} / \mathrm{dL}$ ). Intra-operative was aggravated with uterine atonia and $1300 \mathrm{ml}$ bleeding, therefore subtotal hysterectomy was decided thereafter. Post-operative laboratory results: anemia (hemoglobin level $7.5 \mathrm{~g} / \mathrm{dL}$ ) after blood transfusion, and increased serum creatinine level $(3.5 \mathrm{mg} / \mathrm{dL})$. The second day postoperative, she complained shortness of breath, without fever and oxygen saturation $98 \%$ with nasal cannula canula $3 \mathrm{lpm}$. RTPCR swab test for SARS CoV-2 was performed and results the day after was positive. Patient was admitted in the isolation ward due to the High and Intensive Care Unit was fully occupied. Over the next day, her cardiopulmonary status worsened, and she was in septic shock, blood pressure was $70 / 40 \mathrm{~mm} / \mathrm{Hg}$ with vasopressor. The patient was cardiopulmonary unstable while in preparation for transferring to ICU and declared dead after resuscitation for $30 \mathrm{~min}$.

\section{Case 4}

A 21-year-old woman at 32 weeks of pregnancy was come on her own due to fever, cough, and dyspnea. Initial assessment showed respiratory rate $35 \times / \mathrm{m}$, oxygen saturation $95 \%$, temperature $37.9^{\circ} \mathrm{C}$, and fetal stress. No comorbidities were found from history and examination. RTPCR swab test was positive. Emergency cesarean section was performed and she was initiated with remdesivir and dexamethasone post-operative. Her dyspnea was worsened on the $3^{\text {rd }}$ day, saturation dropped to $50 \%$ with non-rebreathing mask and our team decide to intubate her in ICU. On day 8 her procalcitonin level was increased to $8.97 \mathrm{ng} / \mathrm{mL}$, sputum culture showed bacterial co-infection of Klebsiella pneumoniae and Pseudomonas aeruginosa. Her condition worsened with the need for vasopressor. She was having cardiopulmonary arrest on day 12 with successful resuscitation. The next day she was having another arrest and declared dead after failed resuscitation.

\section{Discussion}

We report four cases of severe-critical COVID19 infection in pregnant women. Patient's family member 
has provided informed consent for publication of the case. Maternal and neonatal data and patient's timeline can be seen in Table 1 and Figure 1. In first case, our patient had a fever complicated with thrombocytopenia. Her DENV infection test was negative, therefore we suspected that thrombocytopenia was caused by COVID-19 infection. Thrombocytopenia can be observed in COVID-19 patients. The possible mechanisms of thrombocytopenia in COVID-19 are: (1) Reduced platelet production by hematopoietic dysfunction and bone marrow growth inhibition and cytokine storm make bone marrow progenitor cell was destroyed, (2) increased platelet destruction by increases of autoantibodies and immune complexes makes platelets will be destroyed as target tissues, and (3) increased platelet consumption by platelet activation, aggregation and wrapping into microthrombus [9]. As mentioned before, risk of VTE is increased in COVID19 infection particularly in pregnant women, therefore initiation of anticoagulants was recommended in this population [6]. D-dimer level of the patient increased to $1290 \mu \mathrm{g} / \mathrm{L}$, the level is above of D-dimer threshold $(1250 \mu \mathrm{g} / \mathrm{L})$ in third-trimester pregnancy [10]. The existence of thrombocytopenia and emergency cesarean section should be undergone, anticoagulant treatment was decided to be postponed and planned to be administered after thrombocyte level increases. Six hours post-operative the patient's condition was worsened and declared dead after unsuccessful cardiopulmonary resuscitation. Pulmonary embolism was suspected as the cause of death because of the sudden onset and increased D-dimer level. Treating patients with increased risk of VTE, thrombocytopenia, and COVID-19 is a therapeutic challenge.
The second and third cases were cases with comorbidities of preeclampsia, obesity, and advanced maternal age. We had difficulty to manage the second patient because she came in sepsis condition. Sepsis likely to occurs on the $10^{\text {th }}$ day from illness onset in non-survivor cases [11], thus in this case the delays in seeking medical care are extremely late. Her history revealed that she never attends antenatal care for this pregnancy. A study in Indonesia by Titaley et al., reported that three factors influencing the decision to do antenatal care: (1) economic and pragmatic reasons; (2) knowledge about maternal and child health; and (3) access to services [12]. Access to services is unlikely to be the factor for delays in seeking medical care since our hospital is located in Jakarta, the Indonesia's capital city. Economic and knowledge factors, particularly during the COVID-19 pandemic, may be the crucial reasons. Related to recent circumstance, we think that many pregnant women will not seek for medical care if she has no obstetric emergency.

The third patient came primary due to preeclampsia and started having symptoms of COVID19 at the $2^{\text {nd }}$ day of admission. Her condition was quickly deteriorated, suffered from sepsis in $<1$ day after having symptoms. Obesity, an important comorbidity, impairs the immune response to COVID-19 infection, specifically by increased anti-inflammatory CD4 T cell subsets Th2 and $T$ regulatory cells, resulting in inhibition of the ability to reduce infection [13]. Accumulation of pro-inflammatory cells, such as macrophages, dendritic cells, cytotoxic $\mathrm{T}$ cells, and Th1 cells in obese individuals also further increase serum inflammatory cytokines, resulting in chronic inflammation conditions [14]. In both second and third cases, we did not give COVID-19 specific

Table 1: Maternal and neonatal data

\begin{tabular}{|c|c|c|c|c|}
\hline Maternal characteristics & Case 1 & Case 2 & Case 3 & Case 4 \\
\hline Age (year) & 33 & 41 & 41 & 21 \\
\hline Gravida and Para & G1P0 & G4P3 & G4P3 & G2P1 \\
\hline Gestational Age (weeks) & $380 / 7$ & Term $^{1}$ & $400 / 7$ & $325 / 7$ \\
\hline $\mathrm{BMI}\left(\mathrm{kg} / \mathrm{m}^{2}\right)$ & 21 & 31.6 & 33.3 & 25.7 \\
\hline Mode of Delivery & Cesarean Section & Cesarean Section & Cesarean Section & Cesarean Section \\
\hline Sign and Symptoms & Fever, 4 days before admission & Dyspnea, 1 day before admission & $\begin{array}{l}\text { Dyspnea, second admission } \\
\text { day }\end{array}$ & $\begin{array}{l}\text { Fever, cough } 3 \text { days, dyspnea } 2 \text { days before } \\
\text { admission }\end{array}$ \\
\hline $\begin{array}{l}\text { Comorbidities and Other Medical } \\
\text { Conditions }\end{array}$ & Thrombocytopenia & $\begin{array}{l}\text { Preeclampsia, PROM, Obesity, } \\
\text { Sepsis }\end{array}$ & $\begin{array}{l}\text { Preeclampsia, Obesity, } \\
\text { Anemia, Uterine Atonia }\end{array}$ & Sepsis \\
\hline Length of stay (day) & 1 & 1 & 3 & 13 \\
\hline $\begin{array}{l}\text { Real-time PCR test for SARS CoV-2 } \\
\text { Laboratory results on admission }\end{array}$ & Positive, preadmission & Positive, post maternal death & Positive, $3^{\text {rd }}$ day & Positive, $1^{\text {st }}$ day \\
\hline 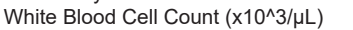 & 4.36 & 30.35 & 20.99 & 7.22 \\
\hline Thrombocyte count $\left(\times 10^{\wedge} 3 / \mu \mathrm{L}\right)$ & 69 & 289 & 315 & 333 \\
\hline Lymphocyte count $\left(\times 10^{\wedge} 3 / \mu \mathrm{L}\right)$ & 0.83 & 0.46 & 0.89 & 1.25 \\
\hline $\begin{array}{l}\text { Serum C-reactive Protein } \\
(\mathrm{mg} / \mathrm{L})\end{array}$ & - & 32.4 & 10.5 & 87.3 \\
\hline Serum ALT (U/L) & 39 & 12 & 11 & 52 \\
\hline Serum AST (U/L) & 64 & 55 & 15 & 103 \\
\hline Serum Creatinine (mg/dL) & 0.80 & 1.30 & 0.90 & 0.60 \\
\hline d-Dimer $(\mu \mathrm{g} / \mathrm{L})$ & 1290 & 25190 & - & 1230 \\
\hline Chest X-ray & $\begin{array}{l}\text { Normal } \\
\text { (previous hospital) }\end{array}$ & Pneumonia & Pneumonia & Pneumonia \\
\hline \multicolumn{5}{|l|}{ Medications } \\
\hline Corticosteroid & Dexamethasone 1x6mg & - & - & Dexamethasone 1x6mg \\
\hline Antiviral & Favipiravir $2 \times 1600 \mathrm{mg}$ & - & - & Remdesivir $1 \times 200 \mathrm{mg}$, changed to $1 \times 100 \mathrm{mg}$ \\
\hline Anticoagulant & - & - & - & UFH2 1×5000 IU \\
\hline Antibiotics & $\begin{array}{l}\text { Ampicillin sulbactam } 4 \times 1.5 \mathrm{~g} \\
\text { empiric }\end{array}$ & Levofloxacin 1x750mg empiric & $\begin{array}{l}\text { Azithromycin } 1 \times 1 \mathrm{~g} \text { changed to } \\
\text { Meropenem } 3 \times 1 \mathrm{~g} \text { empiric }\end{array}$ & $\begin{array}{l}\text { Ceftriaxone } 1 \times 2 \mathrm{~g} \text { empiric, changed to } \\
\text { Meropenem } 3 \times 1 \mathrm{~g} \text { therapeutic }\end{array}$ \\
\hline \multicolumn{5}{|l|}{ Neonatal outcomes } \\
\hline $\begin{array}{l}\text { Apgar score, } \\
1 \mathrm{~min}-5 \mathrm{~min}\end{array}$ & $8 / 9$ & IUFD & $8 / 9$ & $8 / 9$ \\
\hline Birth weight $(\mathrm{g})$ & $2650 \mathrm{~g}$ & $4900 \mathrm{~g}$ & $3600 \mathrm{~g}$ & $2135 \mathrm{~g}$ \\
\hline Infected with SARS-Cov-2 & Negative & - & Negative & Negative \\
\hline
\end{tabular}




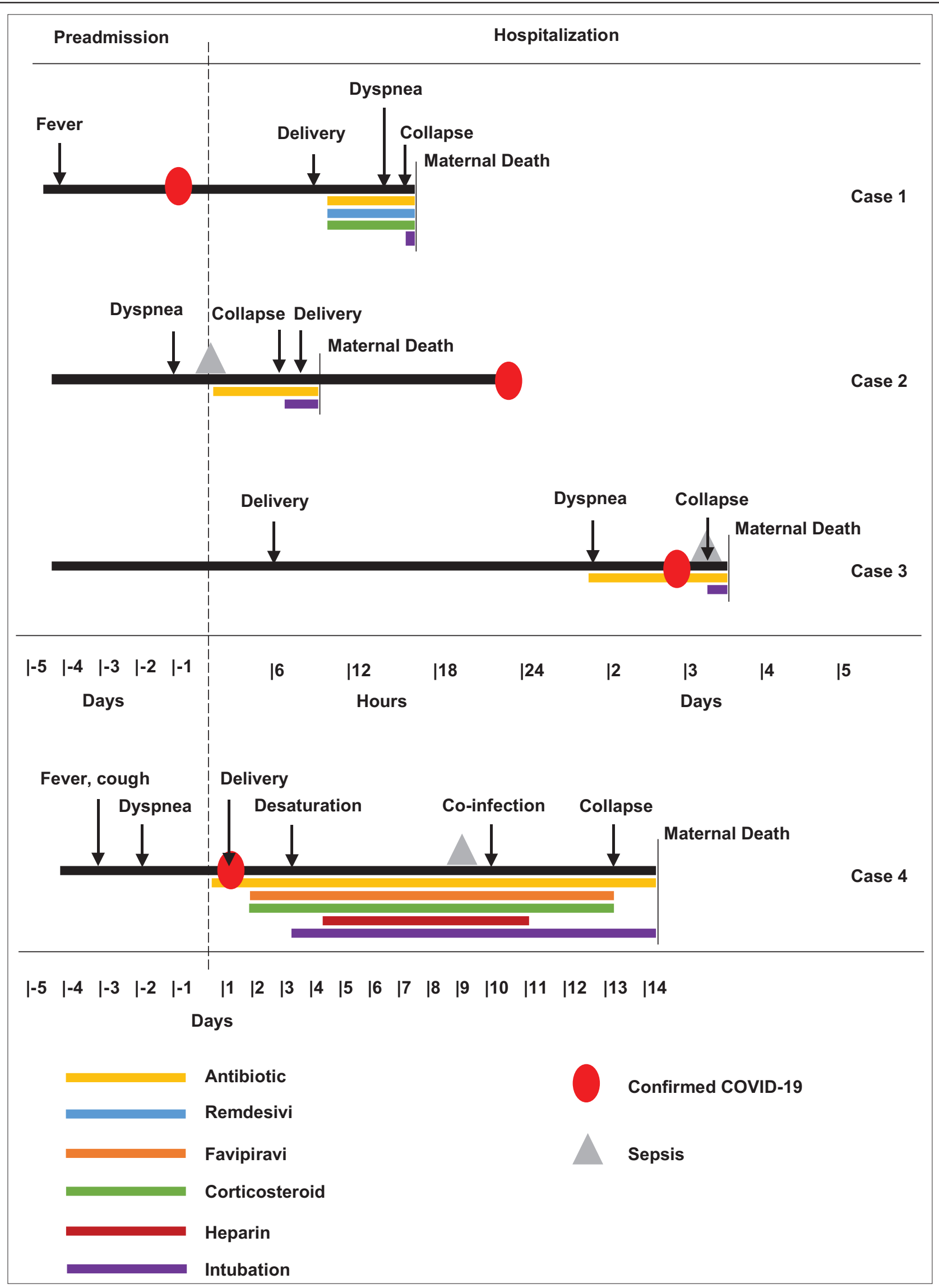

Figure 1. Summary of Patients' Timeline

medications because of the limitation of our RTPCR test. In the second case RTPCR result was completed almost a full day after her death, and in the third case completed just $<1$ day before her death. Limited intensive care facilities also become a problem where we could not transfer the third patient to high or intensive care unit. 
Fourth patient was complicated with sepsis caused by bacterial co-infection. Antibiotics correspond with her culture results and antiviral was given but did not responded. Co-infection can contribute to the poor prognosis for patients with COVID-19 [11], even though the incidence was reported low and the findings do not support the routine use of antibiotics [15]. As of January 2021, medications recommendation for severe or critical COVID-19 cases are dexamethasone and remdesivir (combined with/without baricitinib) [16]. In specific population of pregnant women, only two medications were recommended, remdesivir and corticosteroids [16]. Remdesivir demonstrated a high rate of clinical recovery with low rate serious adverse events [17], and oral prednisolone or intravenous hydrocortisone were recommended due to dexamethasone trait to crosses the placenta [18]. Baricitinib was reported to be safe in pregnant women in a case report [19], but its usage for COVID-19 medication in pregnant women population still needs further studies. Vertical transmission of COVID-19 infection may be occurred, although rare [20]. Fortunately, there was no vertical transmission in all cases, confirmed by RTPCR nasooropharyngeal swab.

\section{Conclusion}

In summary, these four cases were our experiences of treating severe-critical COVID-19 cases in pregnant women that ended with maternal death during November 2020 until January 2021. Limited information and studies for COVID-19 management in pregnant women, particularly in complicated cases with comorbidities is challenging for obstetricians. Furthermore, in middle-income countries like Indonesia, the healthcare facilities and resources such as COVID19 testing capacity, negative pressure isolation room, operating room, and ICU are limited. Based on our experience, recommendations in treating pregnant women with COVID-19 are to confirm the diagnosis (by real-time PCR from throat swab) and define the degree of severity of COVID-19 as soon as possible; thromboprophylaxis should be offered and administered; in severe or critical cases do not delay medications, remdesivir and steroids could be recommended; management should be individualized in the presence of comorbidities or accompanying disease weighing the benefit and risks, and communicate with the family regarding the possible risk of vertical transmission.

\section{References}

1. World Health Organisation. WHO Director-General's Opening Remarks at the Media Briefing on COVID-19-11 March 2020.
Geneva: World Health Organisation; 2020. Available from: https://www.who.int/director-general/speeches/detail/whodirector-general-s-opening-remarks-at-the-media-briefing-oncovid-19---11-march-2020. [Last accessed on 2021 Jan 12]. https://doi.org/10.1093/ww/9780199540884.013.u23682

2. World Health Organization. WHO Coronavirus Disease (COVID-19) Dashboard. Geneva: World Health Organisation; 2021. Available from: https://www.covid19.who.int/table. [Last accessed on 2021 Jan 12].

3. Di Guardo FD, Di Grazia FM, Di Gregorio LM, Zambrotta E, Carrara G, Gulino FA, et al. Poor maternal-neonatal outcomes in pregnant patients with confirmed SARSCov2 infection: analysis of 145 cases. Arch Gynecol Obstet. 2021;3:1-6. https:// doi.org/10.1007/s00404-020-05909-4

4. World Health Organization. Corticosteroids for COVID-19. Geneva: World Health Organization; 2021. Available from: https://www.apps.who.int/iris/rest/bitstreams/1299344/retrieve. [Last accessed on 2021 Jan 14].

5. Takemoto ML, Menezes MO, Andreucci CB, Knobel $R$, Sousa L, Katz L, et al. Clinical characteristics and risk factors for mortality in obstetric patients with severe COVID-19 in Brazil: A surveillance database analysis. BJOG. 2020;127:1618-26. https://doi.org/10.1111/1471-0528.16470

6. Royal College of Obstetricians and Gynaecologists, Coronavirus (COVID-19) Infection in Pregnancy; 2021. Available from: https:// www.rcog.org.uk/globalassets/documents/guidelines/2020-1014-coronavirus-covid-19-infection-in-pregnancy-v12.pdf. [Last accessed on 2021 Jan 14].

7. Centers for Disease Control and Prevention, Information for Clinicians on Investigational Therapeutics for Patients with COVID-19. Available from: https://www.cdc.gov/ coronavirus/2019-ncov/hcp/therapeutic-options.html. [Last accessed on 2021 Jan 14].

8. Horby P, Lim WS, Emberson JR, Mafham M, Bell JL, Linsell L, et al. Dexamethasone in hospitalized patients with Covid-19 preliminary report. N Engl J Med 2020;384(8):693-704. PMid:32678530

9. Xu P, Zhou Q, Xu J. Mechanism of thrombocytopenia in COVID19 patients. Ann Hematol. 2020;99(6):1205-8. https://doi. org/10.1007/s00277-020-04019-0 PMid:32296910

10. Zalpour A, Hanzelka K, Patlan JT, Rozner MA, Yusuf SW. Saddle pulmonary embolism in a cancer patient with thrombocytopenia: A treatment dilemma. Cardiol Res Pract. 2011;2011:835750. https://doi.org/10.4061/2011/835750 PMid:21234423

11. Zhou F, Yu T, Du R, Fan G, Liu Y, Liu Z, et al. Clinical course and risk factors for mortality of adult inpatients with COVID-19 in Wuhan, China: A retrospective cohort study. Lancet 2020;395(10229):1054-62. https://doi.org/10.1016/ s0140-6736(20)30566-3

PMid:32171076

12. Titaley CR, Hunter CL, Heywood P, Dibley MJ. Why don't some women attend antenatal and postnatal care services? A qualitative study of community members' perspectives in Garut, Sukabumi and Ciamis districts of West Java Province, Indonesia. BMC Pregnancy Childbirth. 2010;10:61. https://doi. org/10.1186/1471-2393-10-61

13. Van der Weerd K, Dik WA, Schrijver N, Schewitzer DH, Langerak AW, Drexhage HA, et al. Morbidly obese human subjects have increased peripheral blood CD4+ $T$ cells with skewing toward a treg-and Th2-dominated phenotype. Diabetes. 2012;61(2):401-8. https://doi.org/10.2337/db11-1065 PMid:22228716

14. Popkin BM, Du S, Green WD, Beck MA, Algaith T, Herbst $\mathrm{CH}$ et al. Individuals with obesity and COVID-19: Aglobal perspective 
on the epidemiology and biological relationships. Obes Rev. 2020;21(11):e13128. https://doi.org/10.1111/obr.13128 PMid:32845580

15. Lansbury L, Lim B, Baskaran V, Lim WS. Co-infections in people with COVID-19: A systematic review and meta-analysis. J Infect. 2020;81(2):266-75. https://doi.org/10.1016/j.jinf.2020.05.046 PMid:32473235

16. National Centre for Infectious Diseases. Interim Treatment Guidelines for COVID-19. Available from: https://www.ncid.sg/ Documents/Interim\%20Treatment\%20Guidelines\%20for\%20 COVID-19\%20v4\%20\%2831\%20Aug \%202020\%29-\%20 final.docx\%20for\%20upload.pdf, 2021. [Last accessed on 2021 Jan 19].

17. Burwick RM, Yawetz S, Stephenson KE, Collier AR, Sen P, Blackburn BG, et al. Compassionate Use of remdesivir in pregnant women with severe Covid-19. Clin Infect Dis. 2020;8:ciaa1466.
PMid:33031500

18. Saad AF, Chappell L, Saade GR, Pacheco LD. Corticosteroids in the management of pregnant patients with coronavirus disease (COVID-19). Obstet Gynecol. 2020;136(4):823-6. https://doi. org/10.1097/aog.0000000000004103

PMid:32769659

19. Constanzo G, Firinu D, Losa F, Deidda M, Barca MP, Del Giacco $S$. Baricitinib exposure during pregnancy in rheumatoid arthritis. Ther Adv Musculoskel Dis. 2020;12:1-3. https://doi. org/10.1177/1759720×19899296

PMid:32071617

20. Fenizia C, Biasin M, Cetin I, Vergani P, Mileto D, Spinillo A, et al. Analysis of SARS-CoV-2 vertical transmission during pregnancy. Nat Commun. 2020;11(1):5128. https://doi. org/10.1038/s41467-020-18933-4

PMid:33046695 